Obrist, D., et al. Nature, 2017, 547, 201-204 (accepted version) https://doi.org/10.1038/nature22997

\title{
1 Tundra uptake of atmospheric elemental mercury drives Arctic mercury 2 pollution
}

3

4 Authors: Daniel Obrist ${ }^{1,2 *}$, Yannick Agnan ${ }^{2,3}$, Martin Jiskra ${ }^{4}$, Christine Hedge ${ }^{2}$, Dominique

5 Colegrove $^{5}$, Jacques Hueber $^{5}$, Christopher Moore $^{2,6}$, Jeroen Sonke ${ }^{4}$, Detlev Helmig ${ }^{5}$

7 Affiliations:

$8{ }^{1}$ Department of Environmental, Earth, and Atmospheric Sciences, University of Massachusetts, 9 Lowell, MA 01854, USA

10 2Division of Atmospheric Sciences, Desert Research Institute, 2215 Raggio Parkway, Reno, 11 Nevada 89512, USA.

$12{ }^{3}$ Milieux Environnementaux, Transferts et Interactions dans les hydrosystèmes et les Sols 13 (METIS), UMR 7619, Sorbonne Universités UPMC-CNRS-EPHE, 4 place Jussieu, F-75252 Paris, 14 France.

$15{ }^{4}$ Geosciences Environnement Toulouse, CNRS/OMP/Université de Toulouse, 14 Avenue Edouard 16 Belin, 31400 Toulouse, France.

$17{ }^{5}$ Institute of Arctic and Alpine Research (INSTAAR), University of Colorado, 4001 Discovery 18 Drive, Boulder, Colorado 80309, USA.

$19{ }^{6}$ Gas Technology Institute (GTI), 1700 S Mount Prospect Road, Des Plaines, Illinois 60018, USA. 20

21

$22 *$ Corresponding Author: E-mail: Daniel_obrist@uml.edu 
Anthropogenic activities have led to largescale mercury (Hg) contamination in the Arctic ${ }^{1-3}$ so that $\mathrm{Hg}$ tissue levels in modern-day wildlife including falcon and eagle feathers, polar bear hairs, and beluga whale teeth, are enhanced up to 10-fold ${ }^{4-6}$. High Arctic Hg contamination has been attributed to unique sea-salt-induced chemical cycling of $\mathbf{H g}$, termed Atmospheric Mercury Depletion Events (AMDEs), but their impacts are now debated ${ }^{2,7}$ and are largely unknown away from the coast. Furthermore, wet deposition measurements in the Arctic show some of the lowest $\mathrm{Hg}$ deposition via precipitation worldwide ${ }^{8}$ raising questions as to the sources of high Arctic Hg exposure. Based on the most comprehensive $\mathrm{Hg}$ deposition mass balance study so far, here we show that the main source of $\mathrm{Hg}(\mathbf{7 1 \%})$ in the interior Arctic tundra is derived from gaseous elemental $\mathrm{Hg}\left(\mathrm{Hg}^{0}\right)$ deposition, rather than deposition via precipitation or AMDEs - which are both minor. Deposition of $\mathbf{H g}^{\mathbf{0}}$, the form ubiquitously present in the global atmosphere, occurs throughout the year, including the Arctic winter, and is enhanced in summer by vegetation $\mathrm{Hg}^{0}$ uptake. The tundra uptake of gaseous $\mathrm{Hg}^{0}$ leads to high soil $\mathrm{Hg}$ concentrations and mass exceeding levels in temperate soils several-fold. Concurrent $\mathrm{Hg}$ stable isotope measurements in the atmosphere, snowpack, vegetation, and soils support that $\mathrm{Hg}^{\mathbf{0}}$ dominates as a source to the tundra, and we hence for the first time provide a fully independent confirmation of $\mathrm{Hg}$ isotope source tracing. Stable isotope data from an inland to coastal transect show high soil Hg consistently derived from $\mathrm{Hg}^{0}$, suggesting that the Arctic tundra forms a globally-important $\mathrm{Hg}$ sink storing up to half the world's soil Hg. High tundra soil Hg also explains why rivers annually transport massive amounts of $\mathrm{Hg}\left(50-80 \mathrm{Mg}^{-1}\right)$ to the Arctic Ocean ${ }^{\text {-11 }}$. Hg stable isotope signatures now also suggest that $\mathrm{Hg}^{0}$ may dominate as sources in mid-latitude ecosystems ${ }^{12-15}$, and we hence call for a focus on monitoring strategies for $\mathrm{Hg}^{0}$ deposition worldwide.

Hg pollution impacts are increasingly controlled by climate-change induced disturbances in aquatic and terrestrial biogeochemistry ${ }^{16}$, with potentially the most significant consequences in the Arctic where warming occurs at a rate almost double the worldwide average ${ }^{17,18}$. Regulatory frameworks such as the recent UNEP Minamata Convention - aimed to reduce $\mathrm{Hg}$ contamination globally ${ }^{19}$ - rely on understanding of $\mathrm{Hg}$ sources, which is currently lacking in the Arctic. The widespread $\mathrm{Hg}$ contamination observed across the Arctic is inconsistent with extremely low atmospheric wet deposition, which in Arctic ecosystems is found to be among the lowest globally. 
Obrist, D., et al. Nature, 2017, 547, 201-204 (accepted version) https://doi.org/10.1038/nature22997

For example, annual wet deposition of $2.1 \pm 0.7 \mu \mathrm{g} \mathrm{m}^{-2} \mathrm{yr}^{-1}$ at Gates of the Arctic National Park in Alaska (Supplemental Table S1) is almost five times lower than wet deposition measured across 99 lower-latitude U.S. locations $\left(9.7 \pm 3.9 \mu \mathrm{g} \mathrm{m}^{-2} \mathrm{yr}^{-1}\right)^{8}$. Also unclear are the origins of vast amounts of $\mathrm{Hg}$ that are annually transferred by Arctic rivers to the Arctic Ocean ${ }^{9}$. These riverine $\mathrm{Hg}$ inputs to the Arctic Ocean, which exceed direct atmospheric deposition ${ }^{10,11}$, stand in contrast to predictions that rank Arctic catchments lowest in terms of watershed $\mathrm{Hg}$ storage globally ${ }^{20}$. Another potential $\mathrm{Hg}$ source, deposition due to sea-salt-induced AMDEs in springtime ${ }^{21}$, long was thought to be responsible for high Arctic Hg deposition. However, AMDEs may cause much smaller net $\mathrm{Hg}$ deposition because most of the deposited $\mathrm{Hg}$ can revolatilize to the atmosphere before snow melts and studies provide inconclusive evidence about their importance for Arctic deposition $^{2,7}$.

Unlike wet deposition and deposition related to AMDEs, both of which are composed of oxidized $\mathrm{Hg}\left(\mathrm{Hg}^{\mathrm{II}}\right)$, deposition of gaseous elemental $\mathrm{Hg}^{0}$ - the form which is subject to long-range atmospheric transport and global atmospheric distribution - is largely unconstrained and not measured by deposition networks. We recently reviewed 132 studies on gaseous $\mathrm{Hg}^{0}$ exchange between the atmosphere and terrestrial surfaces and estimated net global terrestrial $\mathrm{Hg}^{0}$ exchange to exhibit a wide range and large uncertainty, from a net deposition of $500 \mathrm{Mg} \mathrm{yr}^{-1}$ to a net emission (i.e., volatilization from ecosystems to the atmosphere) of $1650 \mathrm{Mg} \mathrm{yr}^{-122}$. The large uncertainty stems from an almost complete lack of whole-ecosystem $\mathrm{Hg}^{0}$ exchange measurements among these studies.

Here we performed a mass balance of atmospheric $\mathrm{Hg}$ deposition in the Arctic tundra - a biome covering $\sim 6 \%$ of the global land surface area - to determine the major $\mathrm{Hg}$ sources in one of the most remote ecosystems worldwide. We conducted a two-year field measurement campaign to constrain atmospheric Hg deposition at Toolik Field station on the North Slope of Alaska, USA, $200 \mathrm{~km}$ inland from the coast representing the interior tundra. We measured net gaseous $\mathrm{Hg}^{0}$ exchange at the ecosystem-level using micrometeorological techniques, wet and dry $\mathrm{Hg}^{\mathrm{II}}$ deposition, and vegetation $\mathrm{Hg}$ inputs from aboveground biomass. We correspondingly measured $\mathrm{Hg}$ stable isotopic signatures in the atmosphere, snowpack, vegetation, and soil, and quantified total mass of $\mathrm{Hg}$ sequestered in tundra snowpack, plants, and soils. We further measured 
Obrist, D., et al. Nature, 2017, 547, 201-204 (accepted version) https://doi.org/10.1038/nature22997

84

atmosphere-snow-soil $\mathrm{Hg}^{0}$ gas concentration profiles to independently verify $\mathrm{Hg}^{0}$ flux exchange and locate zones of atmospheric $\mathrm{Hg}^{0}$ sources and sinks.

Gaseous $\mathrm{Hg}^{0}$ was the dominant form of deposition $\left(6.5 \pm 0.7 \mu \mathrm{g} \mathrm{m}^{-2} \mathrm{yr}^{-1}\right)$ accounting for $71 \%$ of total deposition (Fig. 1). Wet $\mathrm{Hg}^{\mathrm{II}}$ deposition amounted to less than $5 \%$ of $\mathrm{Hg}^{0}$ deposition (Supplemental Table S2; $0.2 \pm 0.1 \mu \mathrm{g} \mathrm{m}^{-2} \mathrm{yr}^{-1}$ ) and even lower than previous low measurements from another Arctic site in Alaska ${ }^{8}$. Atmospheric $\mathrm{Hg}^{\mathrm{II}}$ concentrations were below the detection limit $\left(33 \mathrm{pg} \mathrm{m}^{-3}\right)$ during most of the measured period with the exception of March and early April during AMDEs when concentrations reached nearly $0.5 \mathrm{ng} \mathrm{m}^{-3}$ (Extended Data). We constrained atmospheric $\mathrm{Hg}^{\mathrm{II}}$ dry deposition to $2.5 \mu \mathrm{g} \mathrm{m}^{-2} \mathrm{yr}^{-1}$ (range 0.8 to $2.8 \mu \mathrm{g} \mathrm{m}^{-2} \mathrm{yr}^{-1}$ ) based on periodic measurements of atmospheric $\mathrm{Hg}^{\mathrm{II}}$ concentrations (Supplemental Information). We observed temporarily elevated snow $\mathrm{Hg}$ levels during AMDEs, although the deposited $\mathrm{Hg}$ revolatilized to the atmosphere within days (Supplementary Information).

The dominance of gaseous $\mathrm{Hg}^{0}$ deposition as a source to this ecosystem was independently confirmed by $\mathrm{Hg}$ stable isotope analyses. We comprehensively characterized $\mathrm{Hg}$ stable isotope composition of atmospheric $\mathrm{Hg}^{0}$, snowfall and snowpack, vegetation, organic and mineral soil horizons, and bedrock samples. As observed in previous studies ${ }^{12-15,23,24}$, atmospheric $\mathrm{Hg}^{0}$ and $\mathrm{Hg}^{\mathrm{II}}$, bedrock $\mathrm{Hg}^{\mathrm{II}}$, and $\mathrm{Hg}^{\mathrm{II}}$ deposited through AMDEs have unique $\delta^{202} \mathrm{Hg}, \Delta^{199} \mathrm{Hg}$, and $\Delta^{200} \mathrm{Hg}$ signatures (Fig. 2 and Extended Data). We then quantified relative contributions of different $\mathrm{Hg}$ sources to vegetation and soil samples using endmember mixing models and triple isotopic signatures. Results show that atmospheric gaseous $\mathrm{Hg}^{0}$ is the dominant source of $\mathrm{Hg}$ in vegetation (median: 90\%), organic soils (73\%), and upper mineral soils (55\%). $\mathrm{Hg}^{\mathrm{II}}$ deposition accounted for $10 \%$ to $22 \%$ of $\mathrm{Hg}$ in the two soil compartments; and residual $\mathrm{Hg}^{\mathrm{II}}$ from AMDEs, transferred to the tundra soils after snowmelt, accounted for $0-5 \%$. Geogenic $\mathrm{Hg}$ contributed in a range of $0 \%$ in organic soil horizons to $\sim 40 \%$ in mineral soil horizons. These results confirm direct flux measurements demonstrating that gaseous $\mathrm{Hg}^{0}$ deposition is the dominant source of mercury to the tundra at Toolik Field station. We measured soil Hg stable isotope signatures in three additional tundra sites along a transect from Toolik Field station to the Arctic Ocean (Fig. 2D) and considered values from an additional peat profile from Barrow, $\mathrm{AK}$ at the coast ${ }^{24}$, and found no significant differences in isotope signatures between these soils and soils at Toolik Field station. We hence observed no higher contributions of AMDEs (maximum 5\%) even in soils closer to the coast, and 
Obrist, D., et al. Nature, 2017, 547, 201-204 (accepted version) https://doi.org/10.1038/nature22997

114 show evidence that the source of $\mathrm{Hg}$ in tundra soils is consistently and predominantly derived from 115 atmospheric $\mathrm{Hg}^{0}$ uptake.

116 Continuous flux measurements allowed determination of temporal patterns of $\mathrm{Hg}^{0}$ deposition.

117 Gaseous $\mathrm{Hg}^{0}$ deposition persisted throughout periods of snow cover (Fig. 1), with the exception of 118 March and April when net emission of $\mathrm{Hg}^{0}$ to the atmosphere was observed after AMDEs. From 119 October through mid-May, $\mathrm{Hg}^{0}$ deposition averaged $0.4 \pm 0.4 \mathrm{ng} \mathrm{m}^{-2} \mathrm{~h}^{-1}$ and accounted for $37 \%$ of 120 total annual $\mathrm{Hg}^{0}$ deposition. Gaseous $\mathrm{Hg}^{0}$ concentration profiles in snow and soil air, measured 121 with complementary trace gas systems (see Methods), confirmed that wintertime $\mathrm{Hg}^{0}$ deposition 122 occurred (Fig. 3). Snow pore air $\mathrm{Hg}^{0}$ concentrations were consistently below atmospheric 123 concentrations, and concentrations decreased further from the upper to lower snowpack such that 124 concentrations at the soil-snow interface were less than $50 \%$ of atmospheric levels. Since diffusive 125 126 127 128 129 130 and advective trace gas fluxes are a function of respective concentration gradients, these $\operatorname{Hg}^{0}$ concentration profiles were consistent with a net atmospheric deposition flux of gaseous $\mathrm{Hg}^{0}$ to the tundra ecosystem, providing a third means of verifying atmospheric $\mathrm{Hg}^{0}$ deposition. Further analysis showed that the wintertime $\mathrm{Hg}^{0}$ deposition was driven by a sink below the Arctic snowpack, most likely in the tundra soil (Supplementary Information). Such a soil $\mathrm{Hg}^{0} \operatorname{sink}$ has been observed in a temperate soil, but the mechanism for soil $\mathrm{Hg}^{0}$ uptake remains unclear ${ }^{25}$.

$1321.4 \pm 1.0 \mathrm{ng} \mathrm{m}^{-2} \mathrm{~h}^{-1}$ ) and continued to greatly exceed deposition of all other forms of $\mathrm{Hg}$ combined $133\left(78 \%\right.$ of total summertime deposition). In fact, some of the strongest $\mathrm{Hg}^{0}$ deposition occurred after 134 the spring onset of the tundra vegetation growing season, indicating that tundra vegetation 135 amplified gaseous $\mathrm{Hg}^{0}$ deposition. Clearly identifiable by its $\mathrm{Hg}$ isotope signature (Fig. 2), $\mathrm{Hg}$ in 136 aboveground vegetation was indeed primarily (90\%) derived from atmospheric $\mathrm{Hg}^{0}$ uptake as $138\left(29 \mu \mathrm{g} \mathrm{m}^{-2}\right.$; Table S4) which can subsequently be transferred to tundra soils via plant senescence 139 and litterfall.

140 The dominant and time-extended atmospheric deposition of gaseous $\mathrm{Hg}^{0}$ to the Arctic tundra has 141 implications for local, regional, and global Hg cycling. Deposition of globally ubiquitous gaseous $142 \mathrm{Hg}^{0}$ leads to unexpectedly high $\mathrm{Hg}$ levels in these remote tundra soils. Based on ${ }^{14} \mathrm{C}$ age dating 
Obrist, D., et al. Nature, 2017, 547, 201-204 (accepted version) https://doi.org/10.1038/nature22997

143

144

145

146

147

148

149

150

151

152

153

154

155

156

157

158

159

160

161

162

163

164

165

166

167

168

169

that shows that soils at Toolik Field station are older than 7,300 years (Table S5), deposition of atmospheric $\mathrm{Hg}^{0}$ and accumulation of $\mathrm{Hg}$ in soils must have occurred over millennia. Soil $\mathrm{Hg}$ concentrations in the active layer above the permafrost averaged $138 \pm 15 \mu \mathrm{g} \mathrm{kg}^{-1}$ in organic soil layers and $97 \pm 13 \mu \mathrm{g} \mathrm{kg}^{-1}$ in mineral soil horizons (Table S5), exceeding the $20-50 \mu \mathrm{g} \mathrm{kg}^{-1}$ range observed across temperate and tropical soils several-fold ${ }^{26-28}$. Riverine studies suggest that significant contributions by upland soil sources in the Arctic are needed in order to explain high $\mathrm{Hg}$ loadings ${ }^{9,10}$. The high tundra soil $\mathrm{Hg}$ levels, derived from $\mathrm{Hg}^{0}$ uptake, hence explain the conundrum that watersheds with some of the lowest $\mathrm{Hg}$ wet deposition loads on Earth and limited impacts from AMDEs show elevated $\mathrm{Hg}$ in rivers and widespread $\mathrm{Hg}$ impacts on Arctic wildlife ${ }^{3-}$ 6 .

At the global scale, the Arctic tundra serves as an important repository for atmospheric $\mathrm{Hg}^{0} \mathrm{emitted}^{-}$ at mid-latitudes. Stable isotope analysis across four different tundra soils on the North Slope of Alaska confirm that atmospheric $\mathrm{Hg}^{0}$ dominates as a source and suggests a large-scale $\mathrm{Hg}^{0}$ sink across the Arctic tundra. Although few soil tundra $\mathrm{Hg}$ concentrations are reported elsewhere, our measurements along a $200 \mathrm{~km}$ northern Alaska transect and a few published data also show high soil $\mathrm{Hg}$ concentrations (Table S6). If a soil $\mathrm{Hg}$ pool of $27 \mathrm{mg} \mathrm{m}^{-2}$ at Toolik Field station (Table S5; top $40 \mathrm{~cm}$ ) is representative of the global tundra belt, Arctic tundra soils would contain $\sim 143 \mathrm{Gg}$ of $\mathrm{Hg}$, which would account for almost half the total estimated global soil $\mathrm{Hg}$ pool size of $300 \mathrm{Gg}$ based on temperate studies for this soil depth ${ }^{20,29}$. Further, our study provides the first independent experimental verification of source attribution by $\mathrm{Hg}$ isotope signatures, which at this tundra site show that $\mathrm{Hg}$ stored in vegetation and soils is predominantly derived from atmospheric $\mathrm{Hg}^{0}$ consistent with direct deposition measurements. Recent $\mathrm{Hg}$ stable isotope studies have suggested that gaseous $\mathrm{Hg}^{0}$ deposition may dominate as a source in remote forests of the mid-latitudes ${ }^{12-15}$ as well. We hence call upon regulators and the scientific community to reorganize deposition monitoring ${ }^{30}$ to include deposition of $\mathrm{Hg}^{0}$ which we expect to dominate as a source across remote ecosystems worldwide. 
Obrist, D., et al. Nature, 2017, 547, 201-204 (accepted version) https://doi.org/10.1038/nature22997

\section{Methods:}

The study site is located near Toolik Field station $\left(68^{\circ} 38^{\prime} \mathrm{N}, 149^{\circ} 36^{\prime} \mathrm{W}\right)$, a research station operated by the University of Alaska, Fairbanks. All measurement systems were located in a tussock tundra with underlying soil types characterized as Typic Aquiturbels with active layer depths between 60 and $100 \mathrm{~cm}$. All analyzers and control systems were housed in a temperaturecontrolled field laboratory (Extended Data Fig. E1) built on the tundra, and sampling lines and sensors were routed outside to the tundra sampling locations via heated conduits. This setup allowed year-round measurements of trace gas dynamics including through the Arctic winter without damage from icing, animal disturbances, or other issues.

Overview of key measurements: During two full years, we measured continuous net surfaceatmosphere fluxes of gaseous $\mathrm{Hg}^{0}$ (i.e., the balance of deposition and volatilization), that to our knowledge was conducted year-round previously only in two temperate grassland sites ${ }^{31,32}$. Campaign-style wet deposition measurements composed of $\mathrm{Hg}^{\mathrm{II}}$ species ${ }^{33}$ were conducted approximately every six weeks throughout the two years and included snowfall and rain measurements, surface snow and full snowpack collection, and subsequent analysis of total dissolved $\mathrm{Hg}$ after melting. $\mathrm{Hg}^{\mathrm{II}}$ dry deposition was assessed by pyrolyzer measurements (see below) to quantify atmospheric $\mathrm{Hg}^{\mathrm{II}}$ concentrations multiplied by deposition velocity. $\mathrm{Hg}^{\mathrm{II}}$ dry deposition measurements were conducted only from January through September 2016, but we used auxiliary Arctic studies to constrain mid-winter patterns ${ }^{1,34}$ (see below and Extended Data). In addition, we measured gaseous $\mathrm{Hg}^{0}$ in interstitial air of snowpack and tundra soils at multiple locations and depths in the tundra during two full years to assess atmosphere-snow-soil diffusion profiles and pinpoint active source and sink zones. For this, a snow tower (Fig. E1D; ${ }^{35,36}$ ) was deployed to measure $\mathrm{Hg}^{0}$ gas concentrations in interstitial snow pores at multiple depths in the undisturbed tundra snowpack. In addition, a soil trace-gas system (Fig. E1E ${ }^{37}$ ) consisting of six gas wells provided gaseous $\mathrm{Hg}^{0}$ concentrations in soil pores at three depths each in two tundra soil profiles. During summers, field campaigns were conducted for detailed characterization of concentrations and pool sizes of $\mathrm{Hg}$ in all major ecosystem matrices, including vegetation as well as organic and mineral soil layers. Characterization of $\mathrm{Hg}$ stable isotope compositions were conducted in snow, soils, plants, and the atmosphere to complement source and sink processes of $\mathrm{Hg}$ in this tundra ecosystem. 
Obrist, D., et al. Nature, 2017, 547, 201-204 (accepted version) https://doi.org/10.1038/nature22997

Micrometeorological flux measurements to quantify gaseous $\mathrm{Hg}^{0}$ exchange at the ecosystem level were conducted using an aerodynamic flux method (Fig. E1C). Surface-atmosphere flux was calculated by measurement of concentration gradients in the atmosphere above the tundra in conjunction with atmospheric turbulence parameters as follows:

$$
\mathrm{F}_{\mathrm{Hg}^{0}}=-\frac{\mathrm{k} * \mathrm{u}_{*} * \mathrm{z}}{\phi_{\mathrm{h}}(\mathrm{z} / \mathrm{L})} * \frac{\partial \mathrm{c}\left(\mathrm{Hg}^{0}\right)}{\partial \mathrm{z}}
$$

where $k$ denotes the von Karman constant (0.4), $u_{*}$ the friction velocity, $z$ the measurement height, $\phi_{h}(z / L)$ the universal temperature profile, $L$ the Monin-Obukhov length, and $\partial c\left(H g^{0}\right) / \partial z$ the vertical $\mathrm{Hg}^{0}$ gas concentration gradient. $\mathrm{Hg}^{0}$ concentrations at heights of $61 \mathrm{~cm}$ and $363 \mathrm{~cm}$ above the soil surface were measured through $0.2 \mu \mathrm{m}$ Teflon ${ }^{\circledR}$ inlet filters connected to perfluoroalkoxy (PFA) lines, a setup that measures gaseous $\mathrm{Hg}^{037}$. A valve control system with three-way solenoid valves (NResearch, West Caldwell, NJ, USA) allowed switching between the gradient inlets every $10 \mathrm{~min}$. Solenoids were connected to a set of trace gas analyzers with a total sampling flow of 1.5 L min ${ }^{-1}$. This system included an air mercury analyzer (Model 2537A, Tekran Inc. Toronto, Canada); a Cavity Ring-Down (CRD) greenhouse gas analyzer to measure $\mathrm{CO}_{2}, \mathrm{H}_{2} \mathrm{O}$, and $\mathrm{CH}_{4}$ (Los Gatos Research, San Jose, USA); an $\mathrm{O}_{3}$ analyzer (Model 49C, Thermo Scientific, Waltham, USA); and an $\mathrm{O}_{2}$ analyzer (Model 1440, Servomex, East Sussex, United Kingdom).

Fluxes were calculated only during periods of appropriate turbulence according to Edwards et al. ${ }^{38}$ and periods when $z / L<-0.2$ and $z / L>0.2$ were removed from the data set. The tundra measurement site was bordered by Toolik Lake to the north, and we removed data when flux footprints originated from Toolik Lake or it's edge $\left(0-40^{\circ}\right.$ and $300-360^{\circ}, 27 \%$ of the data). For gap filling of periods when measurements were missing, or when fluxes originated from the nearby lake, or when conditions did not fulfill the criteria for acceptable turbulence to calculate fluxes, we interpolated flux data using the average diel pattern of each respective month. For quality control, sampling lines were confirmed to be free of contamination during each field visit (approximately every six weeks using Hg-free air; Model 1100, Tekran Inc.). In addition, line inter-comparisons were conducted at the same interval to test for line biases between the upper and lower inlet lines; for this, both upper and lower inlet lines were set at the same height and measurements were conducted to assess offset. Line intercomparison tests showed no significant line offsets 
Obrist, D., et al. Nature, 2017, 547, 201-204 (accepted version) https://doi.org/10.1038/nature22997

throughout the study with the exception of one time when a leak was detected and immediately fixed, and fluxes prior to that time were corrected.

A snow tower (Fig. E1D) to measure gaseous $\mathrm{Hg}^{0}$ and auxiliary trace gas concentrations in the undisturbed snowpack at multiple heights was deployed next to the flux tower (approximately 2 $\mathrm{m}$ distant). The snow tower, described in Seok et al. ${ }^{35}$ and Faïn et al. ${ }^{36}$, consists of vertical square aluminum bars with $60 \mathrm{~cm}$ cross arms at five heights that hold a total of 10 sampling inlets. Horizontal crossbars that support air inlets were set at heights of 0, 10, 20,30, and $110 \mathrm{~cm}$ above the soil surface, with the lower four inlets generally buried in snow most of winter to measure snow pore air; the uppermost inlet always was located above the snowpack and measured atmospheric $\mathrm{Hg}^{0}$ gas concentrations. Each crossbar supported a pair of connected air inlets, spaced $60 \mathrm{~cm}$ apart, and fitted with $25 \mathrm{~mm}$ syringe filters with $1 \mu \mathrm{m}$ glass fiber membranes (Pall Life Sciences, Ann Arbor, Michigan, USA) connected to PFA lines. Snow tower lines were connected to a Teflon valve control box and data acquisition system inside the heated laboratory. These lines were connected to a second set of trace gas analyzers, including for gaseous $\mathrm{Hg}^{0}$, ozone (same models as above), as well as a $\mathrm{CO}_{2}$ and $\mathrm{H}_{2} \mathrm{O}$ analyzer (Model LI840A, LI-COR Inc., Lincoln, USA). Sampling flow rates were set between 2.7 and $3.0 \mathrm{~L} \mathrm{~min}^{-1}$, and the sampling sequence was set to extract snow air at each height for 10-min measurement periods so that a full sequence of all five inlet heights was sampled every $50 \mathrm{~min}$. Measurements of ambient air gaseous $\mathrm{Hg}^{0}$ concentrations measured at the top inlet of the snow tower system compared well to ambient air $\mathrm{Hg}^{0}$ concentrations measured by the micrometeorological tower.

A soil trace gas measurement system (Fig. E1E), similar to a system described in Obrist et al. ${ }^{25}$, was deployed to allow monitoring of soil pore trace gases at multiple depths and locations. In the first year, the soil trace gas system consisted of six Teflon wells (63.5 cm length, $10.2 \mathrm{~cm}$ diameter) with inside volumes of $4.2 \mathrm{~L}$. One side of each well was perforated with 65 holes of $0.64 \mathrm{~cm}$ diameter for a total perforated area of $20.6 \mathrm{~cm}^{2}$. The holes were covered with Gore-Tex® membranes and Teflon screens, both of which were held in place by stainless steel brackets and pipe clamps for a watertight seal, allowing gas diffusion into the wells while keeping out soil water. The soil wells were placed at two tundra soil profiles $(10 \mathrm{~cm}, 20 \mathrm{~cm}$, and $40 \mathrm{~cm}$ depths); one profile consisted mainly of organic soil layers and a second mainly of mineral horizons. The six wells were connected by PFA lines to the heated laboratory and connected to the same set of 
Obrist, D., et al. Nature, 2017, 547, 201-204 (accepted version) https://doi.org/10.1038/nature22997

instrumentation to measure trace gas gradients for flux measurements (gaseous $\mathrm{Hg}^{0}, \mathrm{CO}_{2}, \mathrm{H}_{2} \mathrm{O}$, $\mathrm{CH}_{4}, \mathrm{O}_{3}$, and $\mathrm{O}_{2}$ ). The system, operated at a flow rate of $1.51 \mathrm{~min}^{-1}$, was programmed to extract a sequence of soil measurements (10 min. each) only three times per day to reduce the air volume extracted from the soil profile and minimize disturbance and advection effects. Because of water intrusion into the soil gas wells in June 2015, the system was replaced with a different system consisting of $47 \mathrm{~mm}$ Teflon inlet filters with additional inlet holes drilled at the bottom of the filters and mounted upside down in the soil profile at the same six locations. Testing in saturated water showed that the hydrophobic Teflon filters prevented water intrusion into the sampling lines using this inlet configuration. Both soil trace gas systems were extensively tested in $\mathrm{Hg}$-free air and ambient air prior to deployment to confirm that they were free of contamination. These systems showed quick equilibrium with ambient air $\mathrm{Hg}^{0}$ concentrations, and there was no memory effect when switching the sampling lines. Both measurement systems provided the same magnitude and seasonal patterns of gaseous $\mathrm{Hg}^{0}$ soil concentrations (Fig. 3).

Atmospheric $\boldsymbol{H g}^{I I}$ concentrations were measured using a third gaseous mercury analyzer (Model 2537; Tekran Inc.) in conjunction with a pyrolyzer unit. $\mathrm{Hg}^{\mathrm{II}}$ concentrations were calculated by differential measurements of air drawn from an inlet configured to measure gaseous $\mathrm{Hg}^{0}$ (using $0.2 \mu \mathrm{m}$ Teflon inlet filters) and a second inlet stream without a filter routed through a pyrolyzer oven set at $650^{\circ} \mathrm{C}$, whereby all atmospheric $\mathrm{Hg}$ forms were converted into gaseous $\mathrm{Hg}^{0}$ (i.e., measure total $\mathrm{Hg}$ ). A valve switching unit (Model 1110, Tekran Inc.) was used to alternate measurements between total $\mathrm{Hg}$ and gaseous $\mathrm{Hg}^{0}$ measurements every $10 \mathrm{~min}$, and allowed calculating $\mathrm{Hg}^{\mathrm{II}}$ concentrations by difference (similar to Lyman and $\mathrm{Jaffe}^{39}$ ). As a pyrolyzer oven, we modified a particulate mercury speciation module (Model 1135; Tekran Inc., Toronto, Canada) and used a quartz tube filled with quartz chips as pyrolyzer inlet that directly reached the ambient atmosphere for sampling. In addition, the particulate filter inside the glassware was removed, and the quartz tube was filled with quartz chips to increase the surface area and serve as an efficient catalyst. The detection limit of this system, based on three times standard deviation of the blanks, was $33 \mathrm{pg} \mathrm{m}^{-3}$. The pyrolyzer unit was deployed from January through September 2016. Atmospheric $\mathrm{Hg}^{\mathrm{II}}$ concentration measurements were lacking from October through mid-February, but we found undetectable $\left(<0.033 \mathrm{ng} \mathrm{m}^{-3}\right.$ ) or low concentrations (generally $<0.05 \mathrm{ng} \mathrm{m}^{-3}$ ) in other winter months, similar to low or undetectable $\mathrm{Hg}^{\mathrm{II}}$ concentrations outside of periods of AMDEs at 
Obrist, D., et al. Nature, 2017, 547, 201-204 (accepted version) https://doi.org/10.1038/nature22997

288

289

290

291

292

293

294

295

296

297

298

other Arctic locations ${ }^{34}$. For 2015, we assumed similar $\mathrm{Hg}^{\mathrm{II}}$ concentrations as measured in 2016. Negative numbers in the $\mathrm{Hg}^{\mathrm{II}}$ record represent noise levels of differential measurements as well as data are produced during strong fluctuations of total atmospheric $\mathrm{Hg}$ concentrations (i.e., during AMDE depletion recoveries). Atmospheric deposition of $\mathrm{Hg}^{\mathrm{II}}$ was calculated to be $2.5 \mu \mathrm{g} \mathrm{m}^{-2} \mathrm{yr}^{-1}$ based on multiplication of measured $\mathrm{Hg}^{\mathrm{II}}$ concentrations with a proposed deposition velocity for $\mathrm{Hg}^{\mathrm{II}}$ of $1.5 \mathrm{~cm} \mathrm{~s}^{-1}$ over various surfaces ${ }^{40}$, with a range from 0.8 to $2.8 \mu \mathrm{g} \mathrm{m}^{-2} \mathrm{yr}^{-1}$ (based on deposition velocities generally between 0.5 and $\left.1.7 \mathrm{~cm} \mathrm{~s}^{-1}\right)^{41}$. Even lower annual atmospheric $\mathrm{Hg}^{\mathrm{II}}$ deposition has been independently estimated for this area based on nearby Arctic lake studies $(0.1$ $\left.\mu \mathrm{g} \mathrm{m}^{-2}\right)^{1}$. Low wintertime $\mathrm{Hg}^{\mathrm{II}}$ concentrations and deposition are further consistent with extremely low wintertime snowfall $\mathrm{Hg}$ concentrations (on average $0.26 \mathrm{ng} \mathrm{L}^{-1}$; Supplementary Information Table S2) - which are derived from $\mathrm{Hg}^{\mathrm{II}}$ scavenged from the atmosphere. Finally, stable $\mathrm{Hg}$ isotopic signatures were consistent with low amounts of $\mathrm{Hg}^{\mathrm{II}}$ deposition measured at this site.

Atmospheric wet deposition of $\mathrm{Hg}$ (mainly $\mathrm{Hg}^{I I}$ forms) and snow $\mathrm{Hg}^{I I}$ was characterized by frequent collection of surface snow and manual collection of rainfall using trace-metal collection techniques (gloves, acid-cleaned Teflon and stainless steel sampling equipment). Samples were analyzed for $\mathrm{Hg}$ concentrations after filtration with $0.45 \mu \mathrm{m}$ pore size filters. A total of 19 sampling dates were used for calculation of wet deposition loads (Table S2). Surface snow samples (top 3 $\mathrm{cm}$ ) were directly transferred into new, sterile polyethylene sampling bags (Whirl-Pak®; Nasco, Fort Atkinson, WI, USA). Fresh snow was directly taken from the surface into the sampling bags; additional snowpack sampling was performed from the top to the bottom of the snowpack using acid-cleaned stainless steel cutters (Model RIP 11000 cc cutter; Snowmetrics, Fort Collins, CO, USA). In addition, snowpack sampling was performed on five dates using two excavated snow pits each that were sampled using stainless steel snow cutter (RIP 1 cutter $1000 \mathrm{cc}$ ) and then directly transferred to the sterile polyethylene sampling bags (double bags). Each snow pit was sampled at $10 \mathrm{~cm}$-layer increments from the top to the bottom of the snow pit. Per layer, two replicate samples from perpendicular walls of the pit were each pooled together for analysis. Summertime collection of rainwater was performed manually using an acid-cleaned Teflon funnel and Teflon bottles. Determination of total dissolved $\mathrm{Hg}$ was performed according to U.S. EPA Method 1631 for total mercury in water using dual stage gold pre-concentration and an $\mathrm{Hg}$ water analyzer (Model 2600; Tekran Inc., Toronto, Canada). Annual atmospheric wet deposition was 
Obrist, D., et al. Nature, 2017, 547, 201-204 (accepted version) https://doi.org/10.1038/nature22997

calculated using volumetric precipitation measured at Toolik Field Station multiplied by respective snow and rain $\mathrm{Hg}$ concentrations (Table $\mathrm{S} 2$ ). $\mathrm{Hg}_{\text {tot }}$ and $\mathrm{Hg}_{\text {diss }}$ concentrations were determined using Tekran 2600 cold-vapor atomic fluorescence spectrometry (Tekran Instruments Corporation, Toronto, $\mathrm{ON}$, Canada) using a bromine monochloride $(\mathrm{BrCl})$ and hydroxylamine hydrochloride digestion following the EPA method 1631. The detection limits, determined as 3-times the standard deviation of blank samples, averaged $0.08 \mathrm{ng} \mathrm{L}^{-1}$. Recoveries as determined by $5 \mathrm{ng} \mathrm{L} \mathrm{L}^{-1}$ standards analyzed after every 10 samples averaged between 93 and 107\%. Laboratory and field blanks were conducted both for the stainless-stell cutter (using water rinses) and the whirl-pak bags used for snow sampling, and both showed no metal contamination (all blank determinations below detection limits).

Soil and vegetation $\mathrm{Hg}$ concentrations were determined from samples collected during multiple field sampling campaigns in spring through fall 2014, 2015, and 2016. All samples were freezedried, milled, and analyzed according to U.S. EPA method 7473 using a total mercury analyzer (Model MA-2000; Nippon Inc., Takatsuki, Japan) and as described in detail in Obrist et al. ${ }^{26}$. To estimate annual $\mathrm{Hg}$ uptake by vegetation and standing aboveground biomass pools (Table S4), data on vegetation dynamics (aboveground net primary productivity: NPP; and aboveground vegetation biomass) were used from Shaver and Chapin ${ }^{41}$ and Chapin et al. ${ }^{42}$.

Hg Stable isotope measurements were performed on $\mathrm{Hg}$ extracted from subsamples of dried and milled vegetation, soil, and rock samples using a two-step oven combustion system ${ }^{14}$. Snow samples were processed using a purge and trap system described by Sherman et al. ${ }^{23}$ which was scaled up to $20 \mathrm{~L}$ bottles to attain $\mathrm{Hg}$ amounts large enough from low-concentrated snow samples. Sample blanks, recoveries, and Hg isotopic composition of processing standards (NIST-3133) were analyzed (Table E4). Atmospheric gaseous $\mathrm{Hg}^{0}$ was collected continuously from a separate inlet at the flux tower, equipped with a glass fiber filter (as described for snow tower measurements) and a heated PFA line to the field laboratory. Atmospheric gaseous $\mathrm{Hg}^{0}$ (typically sampled at $0.2 \mathrm{lpm}$ for periods of 6-8 weeks) was collected on iodated activated carbon traps (ICtraps, $125 \mathrm{mg}$ ) which were processed with a combustion method adapted from Fu et al. ${ }^{43}$. Gaseous $\mathrm{Hg}^{0}$ breakthrough of IC-traps was measured regularly during the sampling campaign using a Tekran 2537 mercury analyzer and was always below the detection limit $\left(0.05 \mathrm{ng} \mathrm{m}^{-3}\right)$. Procedural blanks, procedural standards, and sample recoveries were measured for quality assurance (Table 
Obrist, D., et al. Nature, 2017, 547, 201-204 (accepted version) https://doi.org/10.1038/nature22997

348

349

350

351

352

353

354

355

356

357

358

359

360

361

362

363

364

365

366

367

368

369

370

371

372

373

374

375

376

377

378

379

380

381

382

383

E1). Hg isotopic ratios were measured by cold vapor - multi-collector inductively coupled plasma mass spectrometry (CV-MC-ICPMS; Neptune, Thermo-Finnigan, Germany) at the Midi-Pyrenees Observatory (Toulouse, France) applying measurement protocols described elsewhere ${ }^{13,43}$.

$\mathrm{Hg}$ isotopic signatures are expressed using common nomenclature of small delta notation for massdependent signatures (MDF):

$\delta^{\mathrm{xxx}} \mathrm{Hg}_{\mathrm{NIST}-3133}=\left(\frac{\left({ }^{\mathrm{xxx}} \mathrm{Hg} /{ }^{198} \mathrm{Hg}\right)_{\text {Sample }}}{\left({ }^{\mathrm{xxx}} \mathrm{Hg} /{ }^{198} \mathrm{Hg}\right)_{\text {NIST }-3133}}-1\right) \times 10^{3}$

where xxx corresponds to masses 199, 200, 201, 202, and 204. Mass-independent Hg isotopic signatures (MIF) are expressed by capital delta notation:

$$
\Delta^{\text {yуy }} \mathrm{Hg}=\delta^{\text {yуy }} \mathrm{Hg}-\left(\delta^{202} \mathrm{Hg} \times s f\right)
$$

where yyy corresponds to the mass of 199, 200, 201, and 204 and $s f$ to the kinetic mass-dependent scaling factors of $0.2520,0.5024,0.7520$, and 1.493 for $\Delta^{199} \mathrm{Hg}, \Delta^{200} \mathrm{Hg}, \Delta^{201} \mathrm{Hg}$, and $\Delta^{204} \mathrm{Hg}$, respectively. Analytical precision and accuracy were assured through repetitive measurements of in-house standards ETH-Fluka $\left(\delta^{202} \mathrm{Hg}=-1.43 \pm 0.19 \%, \Delta^{199} \mathrm{Hg} 0.08 \pm 0.07 \%\right.$ o, $\Delta^{200} \mathrm{Hg} 0.02 \pm 0.07 \%$, 2SD, $\mathrm{n}=38)$ and UM-Almaden $\left(\delta^{202} \mathrm{Hg}=-0.56 \pm 0.10 \%, \quad \Delta^{199} \mathrm{Hg}-0.02 \pm 0.06 \%{ }^{2}, \Delta^{200} \mathrm{Hg}\right.$ $0.01 \pm 0.07 \%$, $2 \mathrm{SD}, \mathrm{n}=9$ ) which were in agreement with previously reported values ${ }^{12-14}$.

\section{References:}

1. Fitzgerald, W. F. et al. Modern and historic atmospheric mercury fluxes in northern Alaska: global sources and Arctic depletion. Environ. Sci. Technol. 39, 557-568 (2005).

2. Douglas, T.A. et al. The fate of mercury in Arctic terrestrial and aquatic ecosystems, a review. Environ. Chem. 9, 321 (2012).

3. AMAP, "AMAP Assessment 2011: Mercury in the Arctic. Arctic Monitoring and Assessment Programme (AMAP)" (Oslo, Norway, 2011).

4. $\quad$ Dietz, R. et al. Time trends of mercury in feathers of West Greenland birds of prey during 18512003. Environ. Sci. Techn. 40, 5911 (2006).

5. Dietz, R. et al. Trend in mercury in hair of Greenlandic polar bears (Ursus maritiumus) during 18922001. Environ. Sci. Techn. 40, 1120 (2006).

6. Outridge, P.M. et al. A comparison of modern and pre-industrial levels of mercury in the teeth of Beluga in the Mackenyie Delta, Northwest Territories, and Walrus at Iglookik, Nunavut, Canada. Arctic, 55, 123 (2002).

7. Johnson, K. P. et al. Investigation of the deposition and emission of mercury in arctic snow during an atmospheric mercury depletion event. J. Geophys. Res. 113, D17, D17304 (2008).

8. NADP 2016. National Atmospheric Depostion Program, Annual Data, all MDN sites. http://nadp.sws.uiuc.edu/data/mdn/annual.aspx (Oct 3, 2016).

9. Schuster P. F. et al. Mercury export from the Yukon river basin and potential response to a changing climate. Environ. Sci. Technol. 45, 9262-9267 (2011). 
Obrist, D., et al. Nature, 2017, 547, 201-204 (accepted version) https://doi.org/10.1038/nature22997

384

385

386

387

388

389

390

391

392

393

394

395

396

397

398

399

400

401

402

403

404

405

406

407

408

409

410

411

412

413

414

415

416

417

418

419

420

421

422

423

424

425

426

427

428

429

430

10. Fisher J. A. et al. Riverine source of Arctic Ocean mercury inferred from atmospheric observations. Nat. Geosci. 5, 499-504 (2012).

11. Dastoor, A. P. \& Durnford, D. A. Arctic Ocean: Is It a sink or a source of atmospheric mercury? Environ. Sci. Technol. 48, 1707-1717 (2014).

12. Demers, J. D., Blum, J.D. \& Zak, D. R. Mercury isotopes in a forested ecosystem: Implications for air-surface exchange dynamics and the global mercury cycle. Global Biogeochem Cy. 27, 222-238 (2013).

13. Jiskra, M. et al. Mercury deposition and re-emission pathways in boreal forest soils investigated with Hg isotope signatures. Environ. Sci. Technol. 49, 7188-7196 (2015).

14. Enrico, M. et al. Atmospheric mercury transfer to peat bogs dominated by gaseous elemental mercury dry deposition. Environ. Sci. Technol. 50, 2405-2412 (2016).

15. Zheng, W., Obrist, D., Weis, D., \& Bergquist, B. A. Mercury isotope compositions across North American forests. Global Biogeochem Cy. 30, 1475-1492 (2016).

16. Krabbenhoft, D. \& Sunderland, E.M. Global Change and Mercury. Science 341, 1457-1458 (2013).

17. Polyakov IV, Alekseev GV, Bekryaev RV, Bhatt U, Colony RL, Johnson MA, et al. Observationally based assessment of polar amplification of global warming. Geophys. Res. Letters 29, 1878 (2002).

18. ACIA, "Impacts of a warming Arctic: Arctic Climate Impact Assessment. ACIA Overview report" (Cambridge University Press, 2004).

19. Selin N.E, Global change and mercury cycling: challenges for implementing a global treaty. Environmental Toxicology and Chemistry 33, 1202 (2014).

20. Smith-Downey, N. V., Sunderland, E. M. \& Jacob, D. J. Anthropogenic impacts on global storage and emissions of mercury from terrestrial soils: Insights from a new global model. J Geophys ResBiogeo. 115, 11 (2010).

21. Steffen, A. et al. A synthesis of atmospheric mercury depletion event chemistry in the atmosphere and snow. Atmos. Chem. Phys. 8, 1445-1482 (2008).

22. Agnan, Y. et al. New constraints on terrestrial surface-atmosphere fuxes of gaseous elemental mercury using a global database. Environ. Sci. Technol. 50, 507-524 (2016).

23. Sherman L. S. et al. Mass-independent fractionation of mercury isotopes in Arctic snow driven by sunlight. Nat. Geosci. 3, 173-177 (2010).

24. Biswas, A. et al. Natural mercury isotope variation in coal deposits and organic soils. Environ. Sci. Technol. 42, 8303-8309 (2008).

25. Obrist, D., Pokharel, A. K. \& Moore, C. Vertical profile measurements of soil air suggest immobilization of gaseous elemental mercury in mineral soil. Environ. Sci. Technol. 48, 2242-2252 (2014).

26. Obrist et al. Mercury distribution across 14 U.S. Forests. Part I: spatial patterns of concentrations in biomass, litter, and soils. Environ. Sci. Technol. 45, 3974-3981 (2011).

27. Smith D.B. et al. Geochemical and mineralogical data for soils of the coterminous United States. U.S. Geological Survey Data Series 801, 386p (2013).

28. Amos H. M. et al. Observational and modeling constraints on global anthropogenic enrichment of mercury. Environ. Sci. Technol. 49, 4036-4047 (2015).

29. Hararuk, O., Obrist, D. \& Luo, Y. Modelling the sensitivity of soil mercury storage to climateinduced changes in soil carbon pools. Biogeosciences 10, 2393-2407 (2013).

30. Sprovieri F, et al. Atmospheric mercury concentrations observed at ground-based monitoring sites globally distributed in the framework of the GMOS network. Atmos. Chem Phys. 16, 11915-11935. (2016).

\section{Methods References}


Obrist, D., et al. Nature, 2017, 547, 201-204 (accepted version) https://doi.org/10.1038/nature22997

31. Fritsche, J. et al. Elemental mercury fluxes over a sub-alpine grassland determined with two micrometeorological methods. Atmos. Environ. 42, 2922-2933 (2008).

32. Castro, M. \& Moore, C. Importance of gaseous elemental mercury fluxes in western Maryland. Atmosphere 7, 110 (2016).

33. Douglas, T. A. et al. Influence of snow and ice crystal formation and accumulation on mercury deposition to the Arctic. Environ. Sci. Technol. 42, 1542-1551 (2008).

34. Cole, A.S. et al. Ten-year trands of atmospheric mercury in the high Arctic compared to Canadian sub-Arctic and mid-latitude sites. Atmsph. Chem. Phys. 13, 1535 (2013).

35. Seok, B. et al. An automated system for continuous measurements of trace gas fluxes through snow: an evaluation of the gas diffusion method at a subalpine forest site, Niwot Ridge, Colorado. Biogeochemistry 95, 95-113 (2009).

36. Faïn, X. et al. Mercury dynamics in the Rocky Mountain, Colorado, snowpack. Biogeosciences 10, 3793-3807 (2013).

37. Moore, C. W., Obrist, D. \& Luria, M. Atmospheric mercury depletion events at the Dead Sea: Spatial and temporal aspects. Atmos. Environ. 69, 231-239 (2013).

38. Edwards, G. C. et al. Development and evaluation of a sampling system to determine gaseous mercury fluxes using an aerodynamic micrometeorological gradient method. J. Geophy. Res.Atmos. 110, (2005).

39. Lyman, S. N. \& Jaffe, D. A. Formation and fate of oxidized mercury in the upper troposphere and lower stratosphere. Nat Geosci 5, 114-117 (2012).

40. Zhang, L., Wright, L. P. \& Blanchard, P. A review of current knowledge concerning dry deposition of atmospheric mercury. Atmos. Environ. 43, 5853-5864 (2009).

41. Shaver, G. R., Chapin, F. S. Production: Biomass relationships and element cycling in contrasting Arctic vegetation types. Ecol. Monogr. 61, 1-31 (1991).

42. Chapin, F. S., Shaver, G. R., Giblin, A. E., Nadelhoffer, K. J. \& Laundre, J. A. Responses of Arctic tundra to experimental and observed changes in climate. Ecology 76, 694-711 (1995).

43. Fu, X. , Heimburger, L.-E. \& Sonke, J. E. Collection of atmospheric gaseous mercury for stable isotope analysis using iodine- and chlorine-impregnated activated carbon traps. J. Anal. At. Spectrom. 29, 841-852 (2014).

Acknowledgements: We thank Toolik Field Station and Polar Field Services staff for their support in setting up field site and maintaining operation for two years, with special thanks to Jeb Timm. We thank Olivia Dillon and Christopher Pearson for support with laboratory analyses, Alexandra Steffen and Steve Brooks for providing additional instrumentation, as well as Roger Kreidberg and Jay Arnone for editorial and technical assistance in manuscript preparation. The Hg isotope work was funded by H2020 Marie Sklodowska-Curie grant agreement No 657195 to MJ and European Research Council grant ERC-2010-StG_20091028 and CNRS-INSU-CAF funding (PARCS project) to JES. 
Obrist, D., et al. Nature, 2017, 547, 201-204 (accepted version) https://doi.org/10.1038/nature22997

471 Author contributions: D.O. and D.H. designed and initiated the project, and M.J., J.S. and D.O.

472 designed and developed the isotope component. All authors were involved in all major field 473 sampling and/or laboratory analyses. Y.A. led data analysis and M.J. led stable isotope sampling 474 and analysis with support by J.S. D.O. led manuscript writing with major support by M.J. Y.A. 475 J.S. and C.M.

476 Additional information: Supplementary Information accompanies this paper at 477 http://www.nature.com/

478 Competing financial interests: The authors declare no competing financial interests.

479 Data availability statement: $\mathrm{Hg}$ Concentration data in plants, soils, precipitation and snowpack 480 generated during this study are included in the Extended Data section as Tables. Stable isotope 481 data are also included in Extended Data and in Supplementary Information. Additional data (e.g., 482 flux data) as well as higher-resolution datasets are available from the corresponding author on 483 reasonable request. 


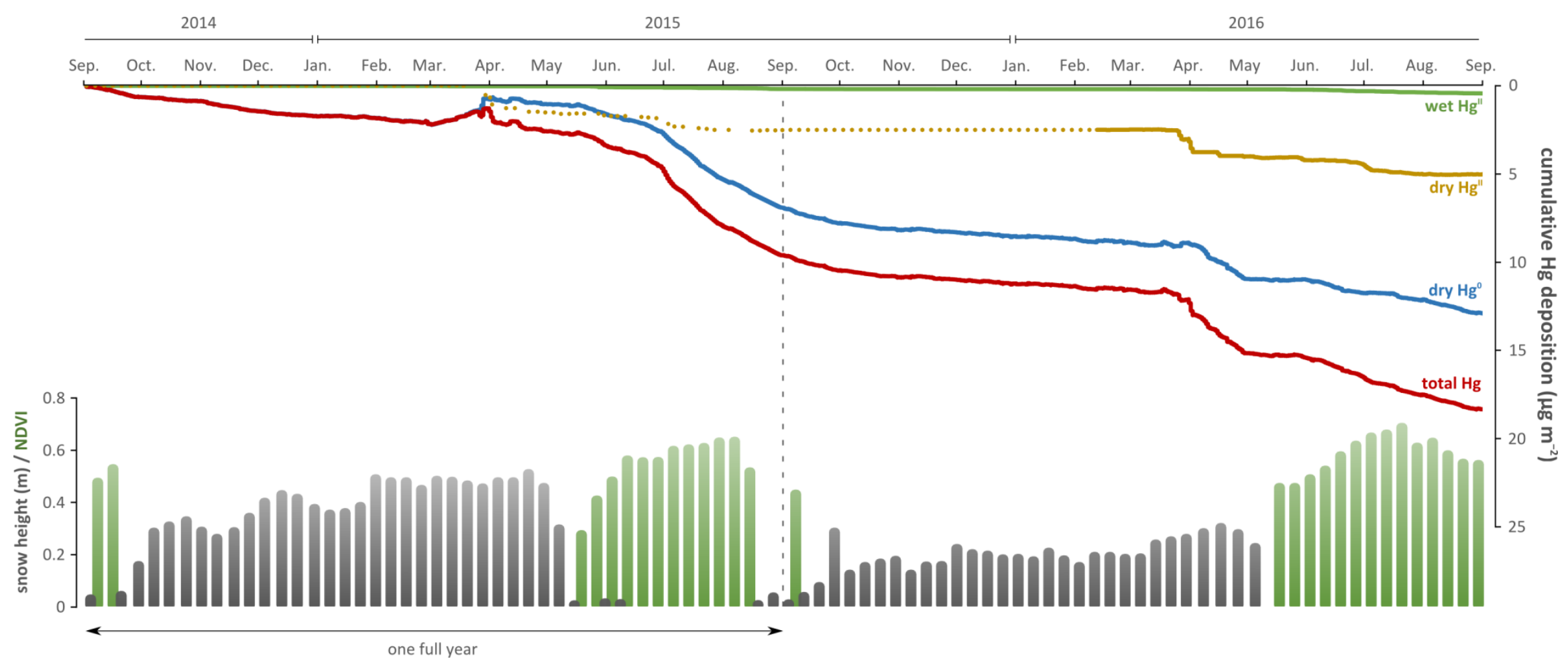

Figure 1. Cumulative atmospheric deposition of major $\mathbf{H g}$ forms in the Arctic tundra. Blue line: gaseous $\mathrm{Hg}^{0}$ flux; green line: wet $\mathrm{Hg}^{\mathrm{deposition}}\left(\mathrm{Hg}^{\mathrm{II}}\right)$; brown line: dry deposition of $\mathrm{Hg}^{\mathrm{II}}$; dashed line shows observations extrapolated when not measured. Bottom panel shows snow heights and vegetation coverage. 
Obrist, D., et al. Nature, 2017, 547, 201-204 (accepted version) https://doi.org/10.1038/nature22997
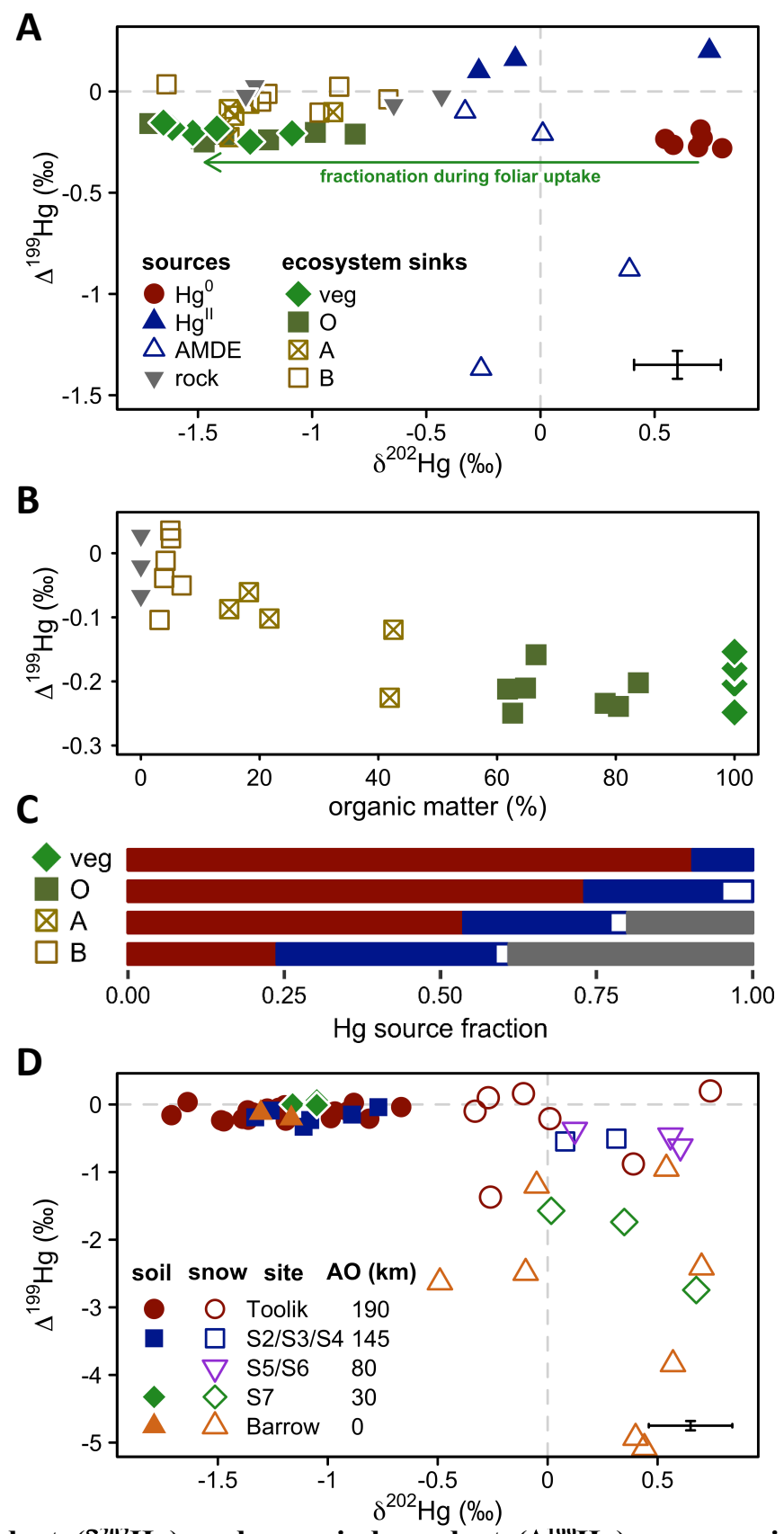

Figure 2 A. Mass-dependent $\left(\delta^{202} \mathrm{Hg}\right)$ and mass-independent $\left(\Delta^{199} \mathrm{Hg}\right)$ mercury isotope signatures in the tundra. Uncertainty (2 SD of replicate standards) shown on lower right. Symbols for sources include: filled circles for atmospheric $\mathrm{Hg}^{0}$; filled triangles for $\mathrm{Hg}^{\mathrm{II}}$ in snow deposited before $\mathrm{Jan} / \mathrm{Feb} 2016$; open triangles for $\mathrm{Hg}^{\mathrm{II}}$ measured in surface snow during periods of AMDEs (Mar/Apr 2016); and filled inverted triangles for geogenic Hg in rock samples. Symbols for tundra samples include: filled diamonds for bulk vegetation; filled squares for organic (O-horizon) soils; and open squares for mineral soils (with cross for A horizons [ $>10 \%$ organic matter] and without cross for B horizons [ $<10 \%$ organic matter]). Arrow represents mass-dependent fractionation of atmospheric $\mathrm{Hg}^{0}$ during foliar uptake. B. Linear correlation of $\Delta^{199} \mathbf{H g}$ with organic matter content, showing that signatures of terrestrial samples can be explained predominantly by binary mixing of the two endmembers geogenic $\mathrm{Hg}$ and vegetation $\mathrm{Hg}$. C. Fraction of respective $\mathrm{Hg}$ sources in vegetation and soils. D. $\boldsymbol{\delta}^{\mathbf{2 0 2}} \mathbf{H g}$ and $\Delta^{199} \mathrm{Hg}$ mercury isotope signatures of soils $(\mathrm{O}, \mathrm{A}, \mathrm{B}$ horizons) and snow (collected during Mar/Apr) along an inland-tocoastal transect. Distance from Arctic Ocean (AO) is given in km. Barrow samples are from ${ }^{23,24}$. 


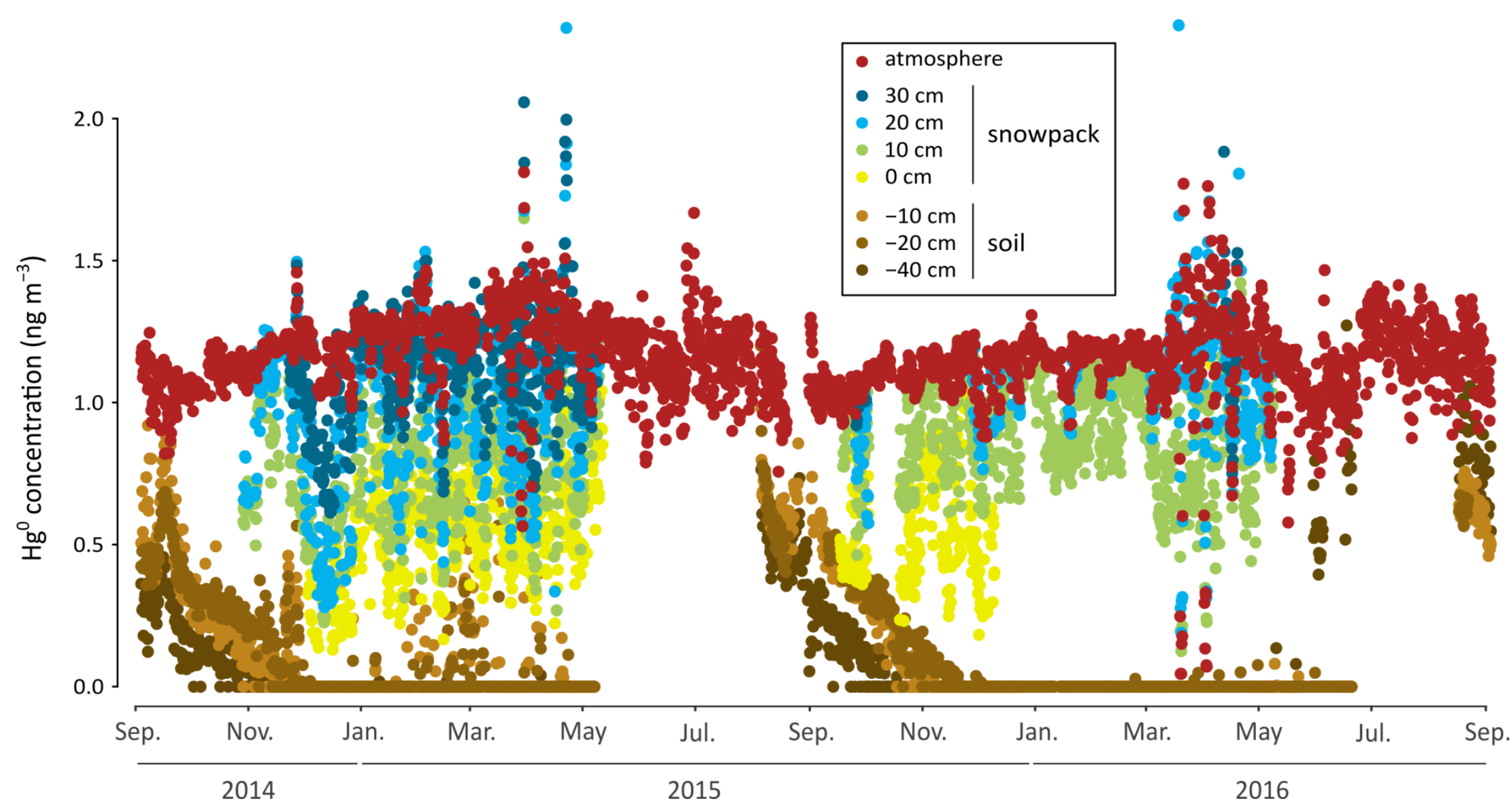

Figure 3. Gaseous $\mathbf{H g}^{0}$ concentrations in the atmosphere, interstitial snow air, and tundra soil pores. Zero-values in soils show concentration measurements below the detection limits. Different symbol colors represent different heights in snowpack and different depths in soils. Snowpack heights (in $\mathrm{cm}$ ) show height in snowpack above the ground surface. Soil depth (in $\mathrm{cm}$, negative numbers) show depth of measurements in soil pores below the ground surface. 